\title{
A Study of the Senior Mentor Peer Counseling and Mutual Assisting System Combined with SFBT model
}

\author{
Yingqun Wang, Haitao Zhao a, ${ }^{*}$, Yueqi Bao \\ Foreign languages school, Changchun University of Technology, Changchun, China. \\ *a798628229@qq.com
}

Keywords: Peer Counseling, Senior System, Solution Focused Brief Therapy.

\begin{abstract}
Based on the worrying background, more and more new explorations and studies of Peer Counseling have been developed for youngsters while there are still a large quantity of psychological problems on campus, according to the disadvantages of other kinds of Peer Counseling system, this paper analyses the typical sources of these defects and puts forward a new system model combining Peer Counseling with Solution Focused Brief Therapy and its feasibility and availability.
\end{abstract}

\section{Introduction}

Nowadays, there are an increasing number of psychological problems among university students, so psycho-education has become a significant research subject. College freshmen got away from the tension state of the college entrance examination could get easier access to trap in a confused period even a period of self-indulgence. More profoundly, due to the heavy double burden of academic pressure and employment pressure, advanced undergraduates have a dilemma of self-doubt, contributing to kinds of psychological problems.

Besides, different from the fundamental goal of learning and getting into a better college in high school, college life is more like a microcosm of society to some extent. Therefore, it is easier to cause contradictions between students, because of lack of interpersonal skills, adequate psychological endurance and family environment.

Moreover, university students come from different provinces have varieties of habits, characteristic and values, which are likely to explode into problems especially in dormitory because of bad dealing with it.

\section{The Actuality and Reason of Peer Counseling}

\subsection{University Students' Psychological Problems}

Indeed, a large proportion of university students' mental health statuses do not look good. A investigate aimed at 126,000 university students indicated that $20.3 \%$ of students had obvious psychological barriers. It shows that a great deal of university students is troubled by negative emotions. Besides, the number of dropouts because of psychological illnesses account for more than 50 percent of all dropouts. From this point of view, spiraling Mental Health Crisis is becoming an important factor in influencing the mental health of university students.

To my mind, the main source caused the worrying situation is a severe shortage of faculty. Nowadays, most of universities only have one or two professional psychology teachers, even own just one psychology teacher who are in the coaching on several campus. Such an extreme disequilibrium of student-faculty ratio made it hard to embark on psychological consultation. Although there are some instructors who are familiar with some psychological strategies to some degree in the college, they still cannot be competent to the task of assisting so many troubled students especially those young instructors. Therefore, professional psychology teachers lack sufficient time and energy to discover and know the potential problems hidden in students on account of the severe shortage of faculty, not to mention timely Psychological counseling. 
Mostly, although, colleges and universities have psychological optional courses, these contents of courses are generally hollow and inflexible; teachers are also not concerned about their students, and prelect by the means of infusionism and moralism, lacking particularly specific training, timeliness, interactivity and enjoyment. Frankly

Yingqun Wang, Haitao Zhao, Yueqi Bao, Changchun University of Technology, Changchun, Jilin, China

speaking, interest blank is a crucial problem towards students. As you can see, because of these factors, an optimistic positive effecthas less opportunity to influence the students who attend.

Secondly, our university students have high self-esteem while lack of security. In consequence, the trouble is that they always keep the diligence up-to-date, because they find that being vigilant about the people they are not familiar with or who come to spread new ideas is psychologically safe and comfortable. Under this circumstance, even if encounter tremendous mental pressures, those students would rather poured out emotions in any other ways to release pressures or have to take another dangerous measure_ hide all the sentiment or annoyance in the depth of heart, all of which are extremely harmful to students' mental health.

\subsection{The Reason of Peer Counseling}

Therefore, we are badly in need of more effective, more convenient and more appealing methods to discover and solve college students' psychological health. According to my study and analysis, most of students will turn to their reliable friends when they encounter difficulties which are hard to deal with. A research made by psychologists also shows that facing problems, 70 percent of people prefer seek help to their companies while only 10 percent of them turn to parents and 8 percent of them turn to the teacher, and the last 12 percent of them seek other ways. These statistics fundamentally reflected on the extremely strong self-esteem and potential independence from university students. Nevertheless, in students' mind, not only teachers and parents are the identification of educator or curator who are dominated in communication, but what they think and do allis standing on the high ground of moral rules_ _ that is the cause of triggering a degree of psychological resistance and disgust. Thus it is almost implausible for students to open their hearts and minds in order to communicate with the teacher or parents.

Differently, on the one hand, the relationships between fellows arequite equal, which helps them to carry on dialogues easier with a harmonious atmosphere; on the other hand, having the similar experiences or horizons, they will resonate with both sides in more themes, devote themselves into deep and hot discussion, and finally come to an agreement.On this occasion, Peer Counseling was born at the right moment and developed into various systems or models.

\subsection{Models of Peer Counseling}

\subsubsection{The Development of Models of Peer Counseling}

Peer Counseling is referring to the course that selected, trained and supervised on-professional psychologists offer psychological counseling to peers who come to turn to. It is not the same as assist with each other, because of a certain degree of professionalism is the basic difference. The actual effect may not compare with professional psychological counseling, but it still make matters in mostly occasion among students.

Peer counseling has been developing since the 1960s, and it has already been the very common way to settle problems in students in America. Theoretically speaking, this method could find psychologicalproblems out quickly and generate timely and effective solutions. However, Peer Counseling also has some defects and inconvenience. As time went by, there were some improved models came out.

Founded in 1971, Peer Counseling center of Stanford University adopted a mode that contains face to face counseling, telephone counseling, suicidal intervention hotline telephones, Grief Work, conflict reconcile and alcohol and drug prevention; In 2007, Fanghua Shi concluded fourforms of activity of Peer Counseling in American schools, that was telephone counseling and Outpatient service consultation, Peer Mediation, Peer Health Education and Peer Tutoring or Mentoring; In The Construction of Peer Counseling Mode ,Yingzi Su put forward three main psychological health 
education modes, including the education model of knowledge about mental health, the mode of Psychological Counseling and Psychotherapy and the mode of Mental Health capacity training; In 2013, Xuelong Yang and Jian Zhu came up with the idea that for purpose of carrying out the psychological self-help and mutual aid, firstly, we were supposed to establish a network of Peer Counseling, enhance the skill training of self-help and mutual aid, adjust evaluation system and motivation mechanism_ it's the foundation of innovation.

Although these Peer Counseling modes have their respective advantages while still exist some vulnerabilities. For example, the channels of communication between peer counselors and students are blocked and inflexible, or peer counselors are not qualified enough so that cannot be recognized by the students, or even reveal students' private information as peer counselors' professional quality is not high enough.

Consequently, in 2016, Liyu Zhang established a Peer Counseling with "he Senior Mentor Peer Counseling and Mutual Assisting System" to get rid of these weaknesses_— "he Senior Mentor Peer Counseling and Mutual Assisting System" means that selects volunteers in senior students. The mode integrates the three essential components of peer counselors, under the guidance of the psychological teacher, allying Psychological Association cadres and freshman assistants with Psychological volunteers. The new team works in the mental guide room as normal work, and all the work or activities are based on each incoming class. Of course this mode indeed provides the convenience for the general students and the peer counselors.

\subsubsection{My Views on Improving the Model of Peer Counseling}

However, from my prospective, Liyu Zhang's mode is just suitable for freshmen. As for sophomores, it may make some difference to some degree. Actually, some potential problems need time to be discovered, such as problems in the dormitory. Besides, the employment pressure and the pressure of taking part in the postgraduate entrance exam always bother junior students and senior students. Take all these factors into consideration, I attempt to form a new mode, that is the senior mentor Peer Counseling and mutual assisting system combined with Solution Focused Brief Therapy (SFBT) model, and select more peer counselors in female students in order to improve Peer Counseling.

\section{The Construction of the Senior Mentor Peer Counseling and Mutual Assisting System Combined with SFBT Model}

\subsection{The Main Theory of Solution Focused Brief Therapy}

Solution Focused Brief Therapy (SFBT), famous for quick short course of treatment, is a short-term psychological therapy rising from the 80 's of the 20th century. It used normally in American high school or universities, for example, apply it to cure depression. Some domestic scholars also have probed into the functions of SFBT in group counseling and career decision-making of university students.

To give effective psychological education to the majority of college students from the aspect of the positive psychology, SFBT encourages students positively; pay them more attention to exceptions in the process of growth. In addition, it is intended to discover one's resources and advantages to arouse the initiative of self-regulation, by which solve the psychological problems.

It is widely recognized that Solution Focused Brief Therapy is a one of essential and necessary skills of professional psychological counselors, which develops to be a unique and prevalent psychotherapy school in the world, owning to its advantages such as easy to learn and spread, convenient to use, short course, and quick effect and less obstacles.

\subsection{The Theoretical Basis of the Senior Mentor Peer Counseling and Mutual Assisting System Combined with SFBT Model}

The senior mentor Peer Counseling and mutual assisting system is to select carefully from excellent sophomores, juniors and seniors as psychological peer counselors. In general, female are more sensitive and careful, which can help them to discover the abnormal situation among university 
students easily. Besides, girls are more easy-going and can calm problem students down. Therefore, these peer counselors get easier access to take good advantages of age and generate the power of examples, improving the effect of spreading psychological knowledge and skills.

\subsection{The structural System of the Senior Mentor Peer Counseling and Mutual Assisting System Combined with SFBT Model}

In our college, set up a Peer Counseling team formed in principal advisors (manage the whole university), college advisors (manage the whole college), freshman class adviser (manage freshmen) and senior psychological volunteers.

Table 1. The Main Skills and its Brief Introductions of Solution Focused Brief Therapy

\begin{tabular}{|c|c|}
\hline Main Skill & Brief Introduction \\
\hline Question & $\begin{array}{l}\text { The change before counseling contains expectation andassumption, which } \\
\text { means that we hope clients'puzzle change a little before counseling and actually it's } \\
\text { normal. }\end{array}$ \\
\hline $\begin{array}{l}\text { Exception } \\
\text { Questions }\end{array}$ & $\begin{array}{l}\text { To developsuccessful solutions which were in the past, helping clients to notice } \\
\text { how they succeeded at that time and realize the serious problems. Then come up with } \\
\text { the feasible solution. }\end{array}$ \\
\hline $\begin{array}{l}\text { Miracle } \\
\text { Questions }\end{array}$ & $\begin{array}{c}\text { To guide students to assume the prospect that problems have been settled in the } \\
\text { future so as to inspire them with hope. Then to find the way to solving problems and } \\
\text { the measure can be takenimmediately. }\end{array}$ \\
\hline $\begin{array}{l}\text { Scaling } \\
\text { Question }\end{array}$ & $\begin{array}{l}\text { To elicit useful details from large perspectives, and use detailed quantitative data } \\
\text { to assist clients to do self-clarification. At the same time, help counselors to access the } \\
\text { effects and improvement direction. }\end{array}$ \\
\hline $\begin{array}{l}\text { Coping } \\
\text { Question }\end{array}$ & $\begin{array}{l}\text { To ask clients where some small executions which is regarded as merited comes } \\
\text { from, and stimulate them to find their potential, power and the methods they used to } \\
\text { overcome difficulties. }\end{array}$ \\
\hline $\begin{array}{l}\text { Relationship } \\
\text { Question }\end{array}$ & $\begin{array}{l}\text { To encourage clients to describe the person who make a difference to them, and } \\
\text { what would they do in the trouble? Then rethink them. }\end{array}$ \\
\hline Praise & $\begin{array}{l}\text { Praising is based on facts, and it comes from clients' description. It has three forms: } \\
\text { direct praise, indirect praise and praise yourself. }\end{array}$ \\
\hline Generalize & $\begin{array}{l}\text { Generalizing is aimed at the problem which clients doubt that they are not in the } \\
\text { normal range of life. Then to retort to the ingrainedproblems they think or sick way } \\
\text { they have. }\end{array}$ \\
\hline Reframing & $\begin{array}{l}\text { To redefine the incidents that clients described, endowing them new and positive } \\
\text { meanings, or specially highlight and reflect on its positive values. }\end{array}$ \\
\hline $\begin{array}{l}\text { Home } \\
\text { Work }\end{array}$ & $\begin{array}{l}\text { Grip the clients' target of counseling,contextand framework, language habits } \\
\text { and change motivation, urging clients to concentrate on develop positive and } \\
\text { exceptional experience and catalyzing clients keep changing. }\end{array}$ \\
\hline
\end{tabular}




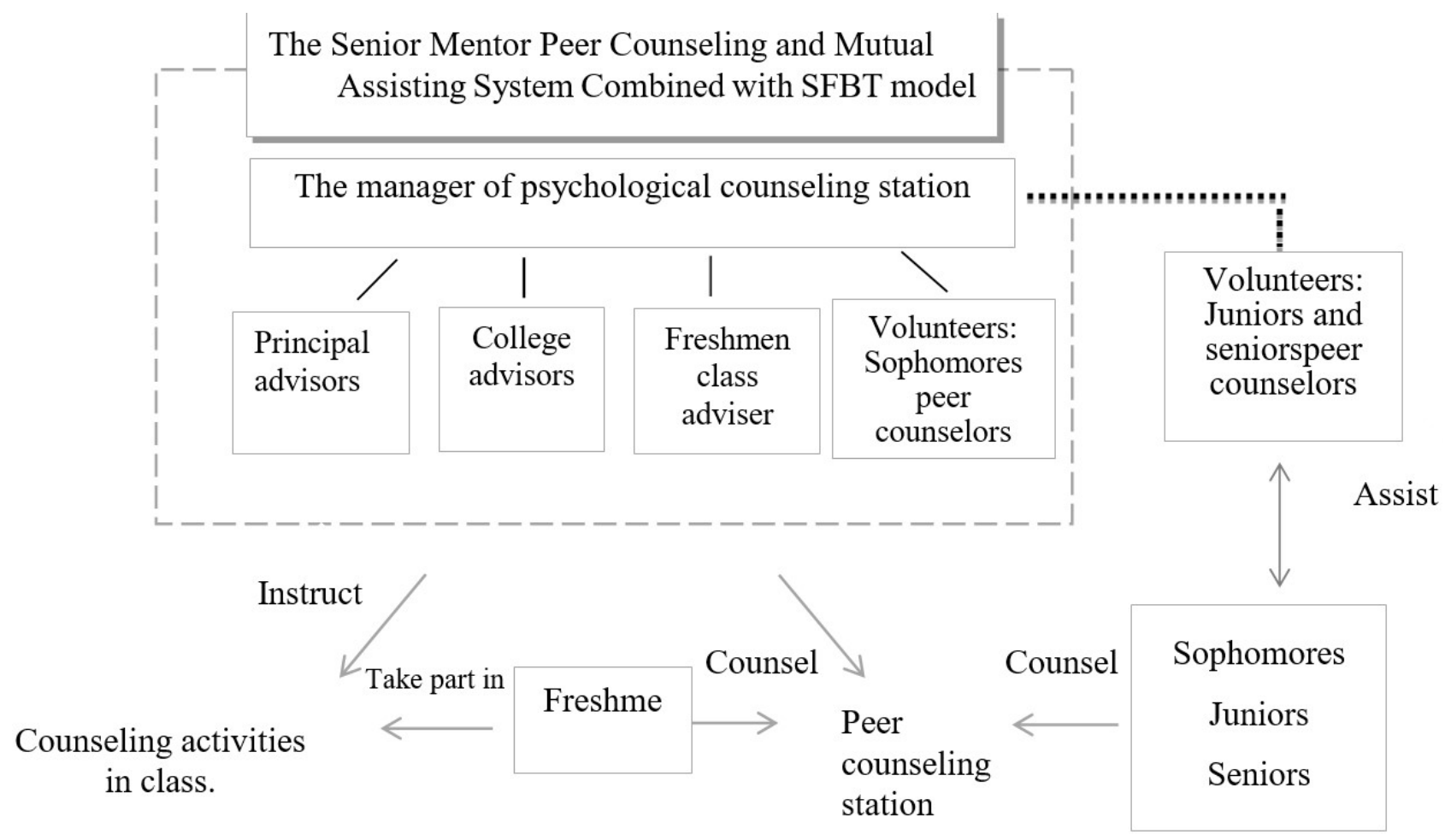

Fig. 1. Structure Chart

Under the instruction of the manager of psychological counseling station, with the help of principal advisors, college advisors, freshman class adviser and senior psychological volunteers, based on freshmen class and peer counseling station, we can hold the training of psychological quality, Psychological Salon, Scene-drama(Psycho-scene-drama) and so on to improve student's psychological knowledge and skills. By doing these ways, kinds of resources are taken full use of and complement each other's advantages at the same time. What's more, the range of target audience and effect of peer counseling are also improved a lot.

In the model, the selected sophomores and a few juniors come to tutor freshmen while most selected juniors and seniors assist to others who are faced with the problems which are the employment pressure and the pressure of taking part in the postgraduate entrance exam. These are the key to create a harmonious atmosphere on campus.

As for main psychological treatment, we choose Solution Focused Brief Therapy, and it is the significant skill we should teach to peer counselors.

\section{The System of Selection and Management of the Senior Mentor Peer Counseling and Mutual Assisting System Combined with SFBT Model}

As Jinsong Zhang said, an extraordinary psychological peer counselor should have appropriate knowledge structure, mature personality and rich Experience. Therefore, the selection of peer counselors must be pretty serious and comprehensive. As we all know, a small leak will sink a great ship. Even a little negligence would make bad effect for those are not qualified in mental.

It is necessary to carry out a rigorous psychological test, interview and inspection in order that we can have a good command of peer counselors' status of moral quality. Moreover, due to the principle of "sophomores tutor freshmen, juniors and seniors assist with each other", the form of recruit is open to everyone, recommendation from class and volunteers should be out of willingness.

Firstly, we need systemic training to make peer counselors can be competent with the tutor and assistant work. The concrete context contains: peer counselors' basic principle, work skills and methods, relevant psychological mental knowledge, direction of work, some solutions to typical psychological problems and some normal therapies such as SFBT.

During training, we'd better analyze actual cases and simulated teaching practice to exercise those psychological counselors, leading them amend the bad habits of expounding something mechanically 
and criticizing. After passing the training, we have the last practice as a final test, and only the qualified volunteers can be a formal peer counselor.

It is also essential to inspect and appraise these formal peer counselors, and reward for those who are best in organizing as support and encouragement.

\section{Conclusion}

On the one hand, the senior mentor Peer Counseling and mutual assisting system Combined with Solution Focused Brief Therapy can deal with freshmen's adaption problems, and settle other kinds of troubles timely, effectively and conveniently; on the other hand, it offers a great platform for juniors and seniors to communicate and interact with each other rationally and solve problems together.

In addition, this mode is combining with Solution Focused Brief Therapy, which is easy to learn and spread, and cultivates lots of qualified peer counselors, alleviating the contradictories between a large group of students and psychological teachers.

Of course, this model also has a little limitation -- it may be hard to work in polytechnic and those college have less female students or some small college which lacks excellent and kind students. Therefore, changing the model according to the environment is a vital method to improve Peer Counseling.

\section{References}

[1]. Lei Ming. The formation of psychological education: connotation, object of study and subject system [j]. Si Chuan: Si Chuan college of science and engineering, 2014.29(3):20-24

[2]. Shi Fanghua, The study of peer counseling in American schools. [J] Healthy education and health promotion, 2007(1):39-43.

[3]. Su Yingzi. The formation of university peer counseling. [J] Yu Lin Normal learning school: Philosophical social science. 2006(4):174.

[4]. Xu Weisu. The study of Solution Focused Brief Therapy towards timely solving female university students. Bulletin of Educational Psychology, 2008.

[5]. Yang Xuelong, Zhu Jian. The model of peer counseling with self-assist. [J]. Zhe Jiang Normal University. High agricultural education. 2013(4):86-88.

[6]. Zhang Liyu. "Upperclassman" Peer Psychological Counseling Model Research and Practice. Jimei University, Xiamen 046000, China

[7]. Zhou li, Lei Li. The inspiration of the mode of peer counselors in American. Theory and Practice of Education. 2016. 